\title{
Pharmaceutical Terms Reflecting the Change in Practice in Japan
}

\author{
Tomoko Watanabe, ${ }^{*, a}$ Yusaku Ohtani, ${ }^{b}$ Toshinori Yamamoto, ${ }^{a}$ Yukio Nemoto, ${ }^{b}$ \\ Yoshiteru IDA, ${ }^{b}$ and John Alexander BACHYNSKY ${ }^{c}$ \\ Departments of Clinical Pharmacy, ${ }^{a}$ and Pharmacognosy and Phytochemistry, ${ }^{b}$ School of Pharmaceutical \\ Sciences, Showa University, 1-5-8 Hatanodai, Shinagawa-ku, Tokyo 142-8555, Japan, \\ and Faculty of Pharmacy and Pharmaceutical Sciences, University of Alberta, ${ }^{c}$ \\ 3126 Dentistry/Pharmacy Centre, Edmonton, Alberta T6G 2N8, Canada
}

(Received July 8, 2004; Accepted December 29, 2004)

\begin{abstract}
The implementation of Iyaku Bungyo, the changed regulations for drug distribution and the proposed change of pharmacy education from a four-year program to a six-year program are rapidly changing the practice of pharmacy. However, pharmacists' activities still remain at the level of simple dispensing and selling of drugs. Also, the terms that describe the essence of pharmacists' activities, such as services in patient care areas are still unclear. In order to solve and improve the problem of terminology for pharmacists' activities the use of terms related to pharmacists' services were examined in historical context. It was found that the terms "Rinsho yakugaku" and "Iryo yakugaku" have been used as having a similar meaning. Further, the term "Iryo yakugaku" was used to denote the comprehensive scope of pharmacists' services including "Rinsho yakugaku". It was verified that "Rinsho yakugaku" is a valid translation for "clinical pharmacy". "Iryo yakugaku" has a more comprehensive translation than "pharmaceutical care”, therefore, it appears that "Iryo yakugaku" is a suitable translation for "pharmaceutical services". Hence, we proposed "Iryo yakugaku" as the English translation for "pharmaceutical services" and "Chiryo yakugaku" as the Japanese translation for "pharmaceutical care". There is a need, however for further clarification and definition of pharmacists' activities.
\end{abstract}

Key words_-Rinsho yakugaku; Iryo yakugaku; clinical pharmacy (Japanese letters); clinical pharmacy (English letters)

\section{INTRODUCTION}

In recent years, medication errors were reported that involved not only physicians and nurses but also pharmacists. ${ }^{1-4)}$ Medication errors that involved a pharmacist are due to pharmacy factors such as drug name confusion (for example: sound-alike name or look-alike name), confusion due to the similar appearance of drug packaging, lack of knowledge about pharmacotherapeutics, and the lack of accuracy in the dispensing system used. Since these medication errors involve basic elements of pharmacy practice, the need for more appropriate pharmacy education and changes in pharmacy practice have been discussed. The need for curriculum renewal has been accepted by the schools of pharmacy, the Ministry of Health, Labour and Welfare, the Ministry of Education, Culture, Sport, Science and Technology, and the Japan Pharmaceutical Association. 5,6)

In the United States, hospital pharmacy practice has shifted from dispensing centered to clinical

\footnotetext{
E-mail: watanabe-t @ pharm.showa-u.ac.jp
}

oriented services that directly involved the patient's drug therapy. New pharmacy curricula reflecting clinical practice were introduced in the schools of pharmacy beginning in the late 1960's. Pharmacy practice has now expanded further with the introduction of pharmaceutical care in which the pharmacists' responsibilities focus on services that improve or maintain a patient's quality of life and that prevent or identify and solve drug related problems. In Japan, attempts have been made to introduce the philosophy of clinical pharmacy and pharmaceutical care practice with little success. It is very difficult for this philosophy to take root in Japan due to the different organizational structure of pharmacy practice as well as cultural factors. Currently, from our review of the literature, it appears that an understanding of these concepts has not occurred, and translations for these terms are unclear.

In Japan, pharmacists working at within the scope of "Iyaku Bungyo" have now reached approximately $50 \%$. Pharmacists are now increasingly employed in community pharmacies (dispensing pharmacies) compared to pharmaceutical companies or hospi- 
tals. ${ }^{7)}$ Therefore, these pharmacists as the health care professionals most responsible for drug use must prevent medication errors and promote the proper use of medication. Consequently, it is important to understand and organize these pharmaceutical terms relating to pharmacotherapy in order that pharmacists may appropriately describe their function.

In this paper, "Rinsho yakugaku" and "Iryo yakugaku" was examined with the purpose of clarifying these terms and defining the scope of pharmacists' services.

\section{METHODS}

A search of frequency and context in the use of pharmaceutical terms "Rinsho yakugaku" and "Iryo yakugaku" was conducted by using the medical literature database Japan Science and Technology Corporation (JICST), National Center for Science Information Systems-Electronic Library Service (NACSIS-ELS), National Library of Medicine (PubMed) Japanese, and also general internet web site MSN and infoseek with the key words "Rinsho yakugaku", "Iryo yakugaku”, "clinical pharmacy (written by Japanese letter Katakana)" and "clinical pharmacy (written by English) " from 1 January 1970 to 31 December 2002. Frequency in the use of and meaning of these terms were examined and analyzed by collecting information from the above resources.

A search for courses described as "Rinsho yakugaku" or "Iryo yakugaku" in the schools of pharmacy were also conducted based on information downloaded from Internet web site (http://www.ipa.or.jp/ pharmacist/daigaku.html) .

Next, presented papers on pharmaceutical studies and pharmacy practice were evaluated for "Rinsho yakugaku" and "Iryo yakugaku" by analyzing the program of the 122nd Congress of the pharmaceutical Society of Japan (2002).

\section{RESULTS}

Frequency in the Use of Terms of "Rinsho Yakugaku" and "Iryo Yakugaku" The number of times the term of "Rinsho yakugaku" was found in JICST was 143, in NACSIS-ELS 65, in PubMed Japanses 170, in msn 1075 and in infoseek 720. Also, the number of times the term of "Iryo yakugaku" was found in JICST was 195, in NACSIS-ELS 104, in PubMed Japanese 170, in msn 21 and in infoseek 1,341 . In JICST and NACSIS-ELS, the frequency in the use of "Iryo yakugaku" was slightly greater than "Rinsho yakugaku", these two terms were found in almost the same number. In PubMed Japanese, these two terms were found in exactly the same number ( $\mathrm{T}$ able 1). The terms of "clinical pharmacy (written by Japanese letter Katakana)" and "clinical pharmacy (written by English)" which seem to refer to "Rinsho yakugaku" or "Iryo yakugaku" were also searched. And the number of "clinical pharmacy (written by Japanese letter Katakana)" found in JICST was 39, in NACSIS-ELS 3, in PubMed Japanese 0, in msn 93 and in infoseek 80 . The frequency of "clinical pharmacy (written by English)" in JICST was 180, in NACSIS-ELS 65, in PubMed Japanese 0, in msn 1,186 and in infoseek 95,536 (Table 1).

In JICST and NACSIS-ELS, although "clinical pharmacy (written by Japanese letter Katakana)" was found in only a few cases, "clinical pharmacy (written by English)" was found in almost the same number as "Rinsho yakugaku" and "Iryo yakuga$\mathrm{ku}$ ". This result would appear to suggest that "clinical pharmacy (written by English)" were previously detected in the literature because Japanese written "clinical pharmacy" was simply written by Japanese letter for English "clinical pharmacy".

In PubMed Japanese, neither "clinical pharmacy (written by Japanese letter Katakana)" nor “clinical

Table 1. The Searched Result for each Database and Internet Web Site

\begin{tabular}{lccccr}
\hline \hline & JICST & NACSIS-ELS & PubMed & msn & infoseek \\
$(2002.08 .08)$ & $(2002.11 .22)$ & $(2002.10 .21)$ & $(2002.10 .07)$ & $(2002.10 .07)$ \\
\hline Rinsho yakugaku & 143 & 65 & 170 & 1075 & 720 \\
\hline Iryo yakugaku & 195 & 104 & 170 & 21 & 1341 \\
\hline Clinical pharmacy (Japanese letter) & 39 & 3 & 0 & 93 & 80 \\
\hline Clinical pharmacy (English) & 180 & 65 & 0 & 1186 & 95536 \\
\hline
\end{tabular}

( ) : access date 
pharmacy (written by English)", were found due to the fact that "clinical pharmacy" were translated to either "Rinsho yakugaku" or "Iryo yakugaku" or these both. Moreover, as can be seen from Table 2, despite the search using the keyword "Rinsho yakugaku", it was combined with "Iryo yakugaku", and so on, thus, it was confirmed that these words had overlap in the same literature. In msn, close to fifty times as many "Rinsho yakugaku" was found compared to "Iryo yakugaku". In infoseek, close to twice as many "Iryo yakugaku", were found as "Rinsho yakugaku', The result from examining the content of the literature searched revealed that the terms of "Rinsho yakugkau" and "Iryo yakugaku" were widely used. However, this result also revealed that the use for these two terms was not consistent and the definitions were unclear. The reason why "clinical pharmacy (written by English)', was often found in msn and infoseek is that the literature and information from oversea were included in the search.

In JICST, NACSIS-ELS and PubMed Japanese, the use of these terms were almost the same however the meaning of those terms was unclear and the meanings were not consistent as shown by overlapping use. It was found in numerous cases that "Rinsho yakuga$\mathrm{ku}$ " and "Iryo yakugaku" were used as having the same meaning and definition.

Chronological Occurrence in the Use of "Rinsho Yakugaku" and "Iryo Yakugaku" The chronological occurrence of the use of the terms "Rinsho yakugaku", and "Iryo yakugaku", were examined. As shown by the data in Fig. 1, it was found that there were three peaks for frequency in the use of these two terms in 1977, 1995-1998 and 2001-2002 (Fig. 1). It was found that the frequency of the use of these terms was relevant to the transition process of Government, Universities or Pharmaceutical Society. Namely, the first peak of the graph coincided with the establishment of small committees on education for examining the "Iryo yakugaku educational curriculum' by the Pharmacy Education Council in 1968, concurrent with the development and presentation of "a design for Iryo yakugaku', by Congress of Japan Pharmaceutical Society in 1971. In other words, in the 1960 's, there were discussions on shifting pharmacy education from a focus on chemistry to one that was patient oriented, and "Iryo yakugaku" education was beginning (Table 3 ).

In the searched literature before the 1990's, as shown in Fig. 2, "Rinsho yakugaku" was 40\%, "Iryo yakugaku" was 10\%, overlapped "Rinsho yakugaku" and "Iryo yakugaku' was $45 \%$. "Rinsho yakugaku" had been used in numerous cases as opposed to "Iryo yakugaku". It was found that the use of these two terms had double meanings based on the terminology used by government, academic staff and professional pharmacy organizations. It does not appear that this situation has changed.

The second peak of the graph from 1995 to 1998; coincided with pharmacists being endorsed as health care practitioners at the second revision of medical law in 1992, the concept of Pharmaceutical care was established and approved by the World Health Organization (WHO) Consultative Conference in Tokyo in 1993, and the statement of "Good Pharmacy Practice", was also declared by the International

Table 2. Example for Overlapping Use of Terms in same Literature

\begin{tabular}{|c|c|c|c|c|}
\hline Literature & Rinsho yakugaku & Iryo yakugaku & $\begin{array}{l}\text { Clinical Pharmacy } \\
\text { (Japanese letter) }\end{array}$ & $\begin{array}{l}\text { Clinical pharmacy } \\
\text { (English) }\end{array}$ \\
\hline Aizawa Y., Pharmacia, 13, 38-39, 1977 & $\bigcirc$ & $\bigcirc$ & & \\
\hline Kasuya Y., Pharmacia, 13, 911, 1977 & $\bigcirc$ & $\bigcirc$ & & \\
\hline Horioka M., Pharmacia, 13, 912-913, 1977 & $\bigcirc$ & $\bigcirc$ & $\bigcirc$ & $\bigcirc$ \\
\hline Kubo S., Pharmacia, 13, 915, 1977 & $\bigcirc$ & $\bigcirc$ & & \\
\hline Komiyama T., Pharmacia, 33, 1997 & $\bigcirc$ & $\bigcirc$ & & \\
\hline $\begin{array}{l}\text { Shibuya, Kondo., Iryo Yakugaku, 28, 28-40, } \\
2002\end{array}$ & $\bigcirc$ & $\bigcirc$ & & $\bigcirc$ \\
\hline Ohnishi et al., Iryo Yakugaku, 28, 57-62, 2002 & $\bigcirc$ & $\bigcirc$ & & $\bigcirc$ \\
\hline $\begin{array}{l}\text { Nishida, Kitada et al., Iryo Yakugaku, 28, } \\
116-125,2002\end{array}$ & $\bigcirc$ & $\bigcirc$ & & $\bigcirc$ \\
\hline
\end{tabular}




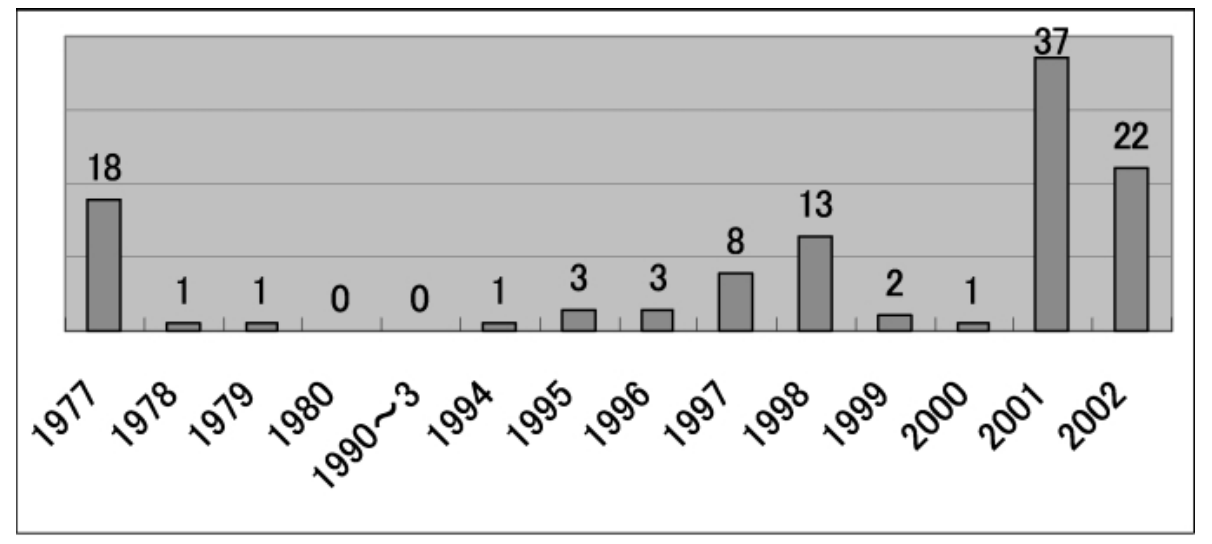

(Total number of literatures : 110 )

Fig. 1. Chronological State in the Use of "Rinsho Yakugaku" and "Iryo Yakugaku"

Table 3. Social Movement related to Pharmacist Activities and Pharmacy Education

\begin{tabular}{|c|c|}
\hline Era & Phenomenon \\
\hline $\begin{array}{c}1873 \\
(\text { Meiji 6) }\end{array}$ & $\begin{array}{l}\text { Established Department of Pharmaceutical Chemistry attached to the Medical School of Daiichi University (The } \\
\text { present Faculty of Medicine, Tokyo University) }\end{array}$ \\
\hline 1874 & Drug seller (The present pharmacist) obtained dispensing authority by Government Controlled Medical Acts \\
\hline 1889 & Issued "Regulation of Drug Distribution and Management"'. Regulated denomination of pharmacist and its role \\
\hline 1893 & Founded The Japan Pharmaceutical Association (integrating all of Japan) \\
\hline $\begin{array}{l}1925 \\
\text { (Taisho 14) }\end{array}$ & Issued "Pharmacist law" \\
\hline $\begin{array}{c}1926 \\
\text { (Showa 1) }\end{array}$ & Established local Pharmaceutical Association. \\
\hline 1943 & $\begin{array}{l}\text { Enacted "New Pharmaceutical Affairs Law". The Japan Pharmaceutical Association belonged to Government In- } \\
\text { stitution. }\end{array}$ \\
\hline 1948 & $\begin{array}{l}\text { Issued "New Pharmaceutical Affairs Law" due to end of the World War 2. The Japan Pharmaceutical Association } \\
\text { united with the Pharmaceutical Society of Japan, and to become corporate juridical person. }\end{array}$ \\
\hline 1949 & Began National Examination for Pharmacy Practitioner. \\
\hline 1956 & $\begin{array}{l}\text { In 1949, Mission of American Pharmaceutical Association came to Japan, and advised revision of laws and educa- } \\
\text { tion, and also advised implementation of Iyaku Bungyo system (separation of prescribing and dispensing), and its } \\
\text { system was legislated. However, its system was not fixed due to numerous incidents. }\end{array}$ \\
\hline 1960 & $\begin{array}{l}\text { Pharmacist's status in the law was separated from the Pharmaceutical Affairs Law. Issued "New Pharmaceutical } \\
\text { Affairs Law" and "New Law for Pharmacist". }\end{array}$ \\
\hline 1962 & To divide the Japan Pharmaceutical Association from the Pharmaceutical Society of Japan. \\
\hline 1966 & $\begin{array}{l}\text { Began a discussion for essence of Pharmacy Education by pharmacy education Committee in Japan Pharmaceutical } \\
\text { Association. }\end{array}$ \\
\hline 1968 & $\begin{array}{l}\text { Prepared "Code of Ethics for Pharmacist"' by Japan Pharmaceutical Association. Established small committee for } \\
\text { "Examination of Iryo Yakugaku Education Program" in convention of pharmacy education. }\end{array}$ \\
\hline 1971 & $\begin{array}{l}\text { Embodiment of "Design of Iryo Yakugaku" was discussed in the Congress of Japan Pharmaceutical Association } \\
\text { and emphasized to correct "No patient pharmacy education" }\end{array}$ \\
\hline 1972 & $\begin{array}{l}\text { To continue to discuss above in the Congress of Japan Pharmaceutical Association. Submitted "Improvement and } \\
\text { extension of length for pharmacy education"' by the Committee of Pharmacy Education. }\end{array}$ \\
\hline 1974 & $\begin{array}{l}\text { The Japan Medical Association declared the policy that would start to implement Iyaku Bungyo in } 5 \text { years. It was } \\
\text { just one step forward for Iyaku Bungyo. }\end{array}$ \\
\hline 1980 & $\begin{array}{l}\text { Stipulated Iryo Yakugaku in revision of standard for pharmacy education by the University Criterion Foundation. } \\
\text { (provided accreditation curriculum for clerkships) }\end{array}$ \\
\hline 1985 & A part of "Medical Law" was revised, and pharmacy and pharmacist was included in the Medical Law. \\
\hline
\end{tabular}


Table 3. Social Movement related to Pharmacist Activities and Pharmacy Education (cont'd)

\begin{tabular}{|c|c|}
\hline Era & Phenomenon \\
\hline $\begin{array}{c}1989 \\
\text { (Heisei 1) }\end{array}$ & Established the Japan Pharmacist Education Center as a foundation. \\
\hline 1990 & $\begin{array}{l}\text { Started "Standard Pharmacy" system that was approved by local Pharmaceutical Association and enacted by } \\
\text { Japan Pharmaceutical Association. }\end{array}$ \\
\hline 1992 & Pharmacist was positioned as a health care practitioner in the second revision of Medical Law. \\
\hline 1993 & $\begin{array}{l}\text { Established the meeting of examining Pharmacy Education on the Ministry of Health, Labour and Welfare in } \\
\text { November. } \\
\text { Established the cooperation meeting of examining pharmacy education revision on the Ministry of Education, Cul- } \\
\text { ture Sport, Science and Technology in December. }\end{array}$ \\
\hline 1994 & To establish the office for promotion of pharmacy education revision in the Japan Pharmaceutical Association. \\
\hline 1995 & Developed "Iryo yakugaku field" in National Examination for pharmacist. \\
\hline \multirow[t]{3}{*}{1996} & $\begin{array}{l}\text { To have } 50 \% \text { of questions related to Iryo Yakugaku in National Examination for Pharmacist. } \\
\text { Established the meeting for Pharmacy Education by the Ministry of Health, Labour and Welfare, the Ministry of } \\
\text { Education, Culture Sport, Science and Technology, the representative of Japan Pharmaceutical Association and the } \\
\text { representative of Japan Hospital Pharmacist Association. }\end{array}$ \\
\hline & $\begin{array}{l}\text { Developed the proposal of New Standard for Pharmacy Education by the meeting of Examining Pharmacy Educa- } \\
\text { tion. }\end{array}$ \\
\hline & Began "Get the Answers"' \\
\hline 1997 & Revised the Code of Ethics for Pharmacist by Japan Pharmaceutical Association. \\
\hline 1998 & Started 4 weeks hospital clerkship for pharmacy students. \\
\hline 1999 & $\begin{array}{l}\text { Established the meeting for Pharmacy Education by the Ministry of Health, Labour and Welfare, the Ministry of } \\
\text { Education, Culture Sport, Science and Technology, the representative of Japan Pharmaceutical Association, the } \\
\text { representative of Japan Hospital Pharmacist Association, the representative of the Dean of the Faculty of Pharma- } \\
\text { cy in National and Public Universities, the Association of the Faculty and School of Pharmacy in private Universi- } \\
\text { ties. }\end{array}$ \\
\hline 2000 & Implemented pharmacy clerkship for pharmacy students. \\
\hline
\end{tabular}

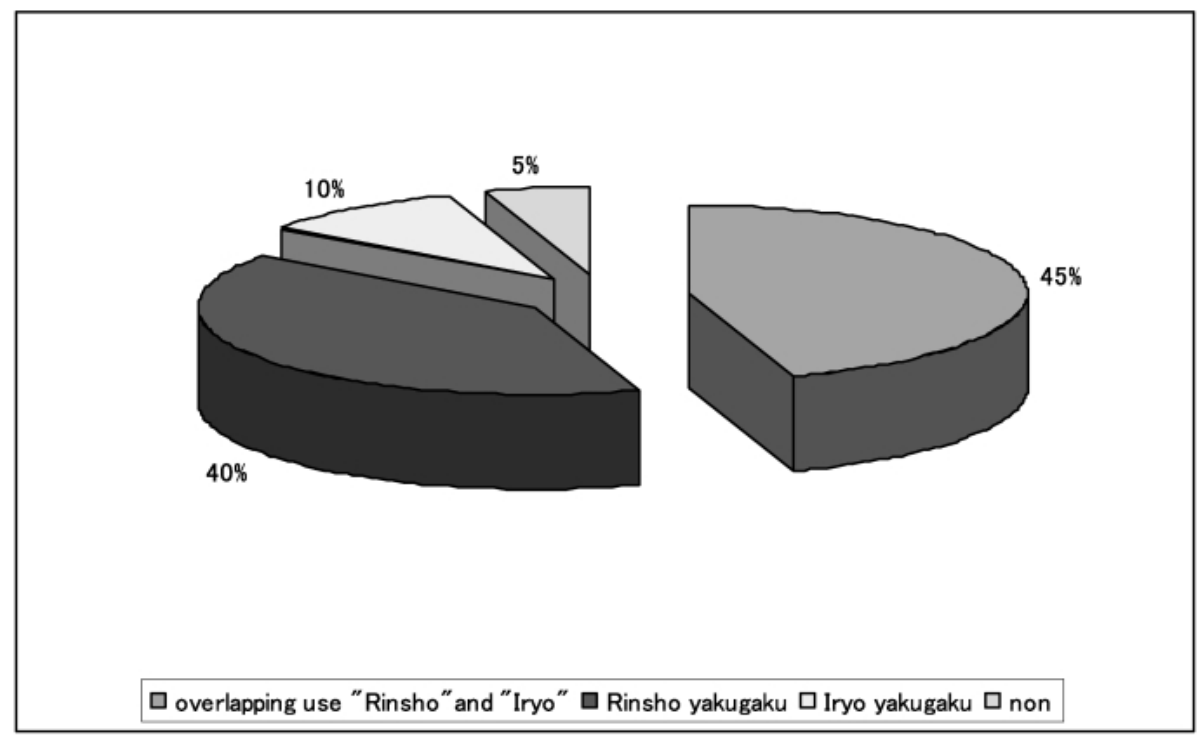

(Total number of literatures : 20)

Fig. 2. The Rate of the Use "Rinsho Yakugaku" and "Iryo Yakugaku" in Searched Literatures before 1990's

Pharmaceutical Federation (FIP) Council Meeting in Tokyo at the same time, moreover, National Examination for Pharmacist Licensure was developed to in- clude the field of "Iryo yakugaku" defined as providing the patient with optimal drug therapy (the number of questions in this field comprised $50 \%$ of the 
total questions in the Examination in 1995). These factors appear to explain this peak. However, the terms "Rinsho yakugaku" and "Iryo yakugaku" had also been used interchangeably at this time.

In the latest peak of the graph for 2001 to 2002, the social events below have occurred:

- Increasing proportion of pharmacists working in community pharmacy (dispensing pharmacy) due to development of Iyaku Bungyo.

- Current review of the pharmacy educational curriculum in each school of pharmacy due to the necessity of "Rinsho yakugaku" or "Iryo yakuga$\mathrm{ku}$ " experiential education.

- Need to review specialty education and competence of pharmacists, because of the impending excess number of pharmacists in the workplace.

- Introduction of a six-year pharmacy education program in Japan in the near future.

This latest peak appears to have relevance to the background above.

In the searched literature after 1990 , as seen from Fig. 3, "Rinsho yakugaku”, was $12 \%$, "Iryo yakugaku" was $26 \%$, overlapped "Rinsho yakugaku" and "Iryo yakugaku" was $18 \%$. This is quite different from the results before 1990's, that is, frequency in the use of "Iryo yakugaku" was more than "Rinsho yakugaku". It appears that the use of "Iryo yakugaku" has become consistent in its use by government departments such as the Ministry of Health, Labour and Welfare, the Ministry of Education, Culture Sports, Science and Technology, Pharmaceutical Associations and so on.

The number of "Rinsho yakugaku" and "Iryo yakugaku" references found demonstrates a chronological change with three peaks illustrating this change. And it was confirmed that each term had differences in its use and definition recognition.

The Implementing of "Rinsho Yakugaku" or "Iryo Yakugaku” Courses in Schools of Pharmacy The survey was completed by 36 of 46 schools of pharmacy in Japan (78.3\%) of those schools of pharmacy, 15 established "Rinsho yakugaku" and 21 established "Iryo yakugaku" courses. "Iryo yakugkau" was found more often compared to "Rinsho yakugaku", as in Fig. 4, especially after 1990. The number of courses designated "Iryo yakugaku" has increased (Fig. 5). This result is similar to the use of terminology, that is, frequency of the use of "Iryo yakugaku” exceeded "Rinsho yakugkau” after 1990.

Even though it was not established how each university chose the course name, it appeared to result from the chronological shift in the use of the terms based on administrative and social convention.

As a result, schools of pharmacy have established courses that related to "Rinsho yakugaku" and "Iryo yakugaku" in the light of administrative and social movement. However, the terminology still mingles both "Rinsho yakugaku" and "Iryo yakugaku",

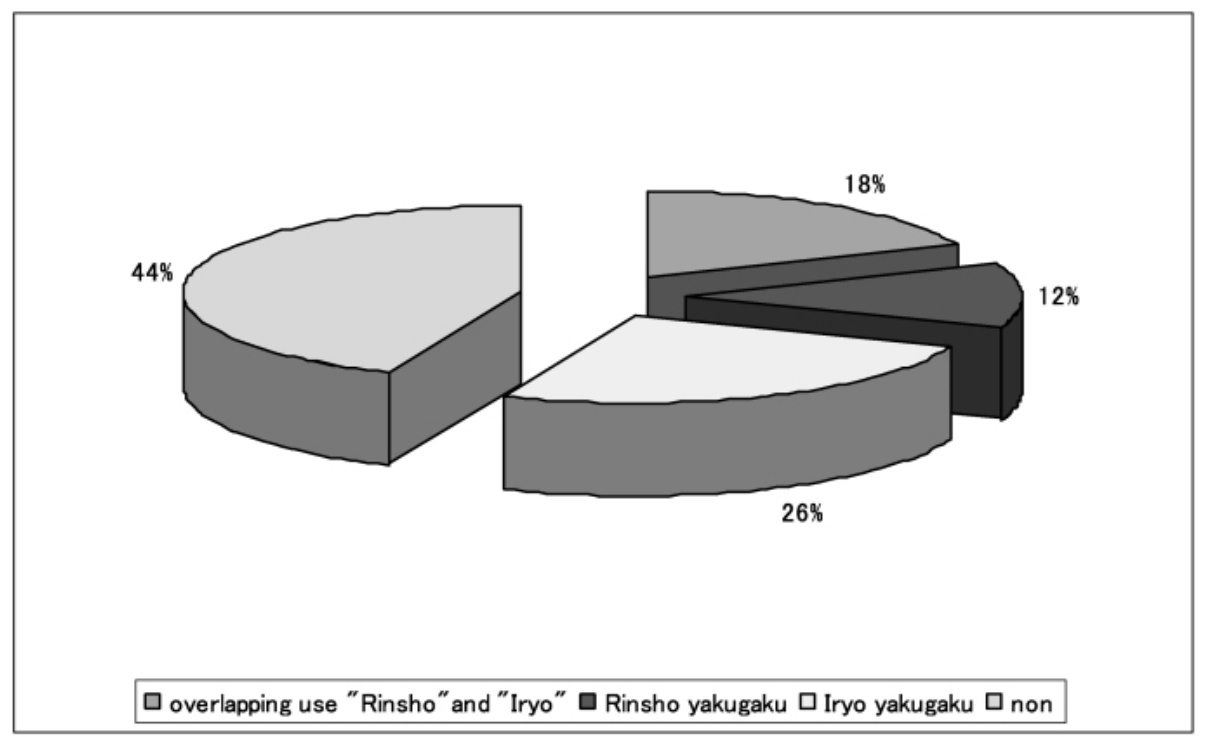

(Total number of literatures : 90)

Fig. 3. The Rate of the Use "Rinsho Yakugaku” and "Iryo Yakugaku”' in Searched Literatures after 1990's 


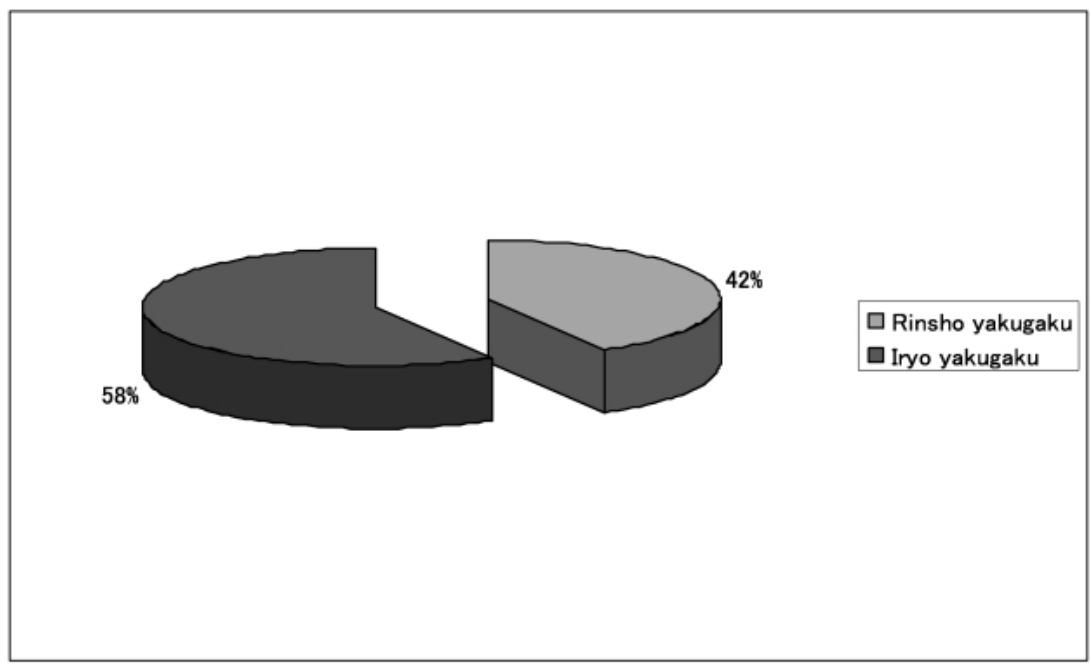

(In 36 Universities, as of 2002)

Fig. 4. The Listing of an Established Course Designated "Rinsho Yakugaku" or "Iryo Yakugaku" in Schools of Pharmacy

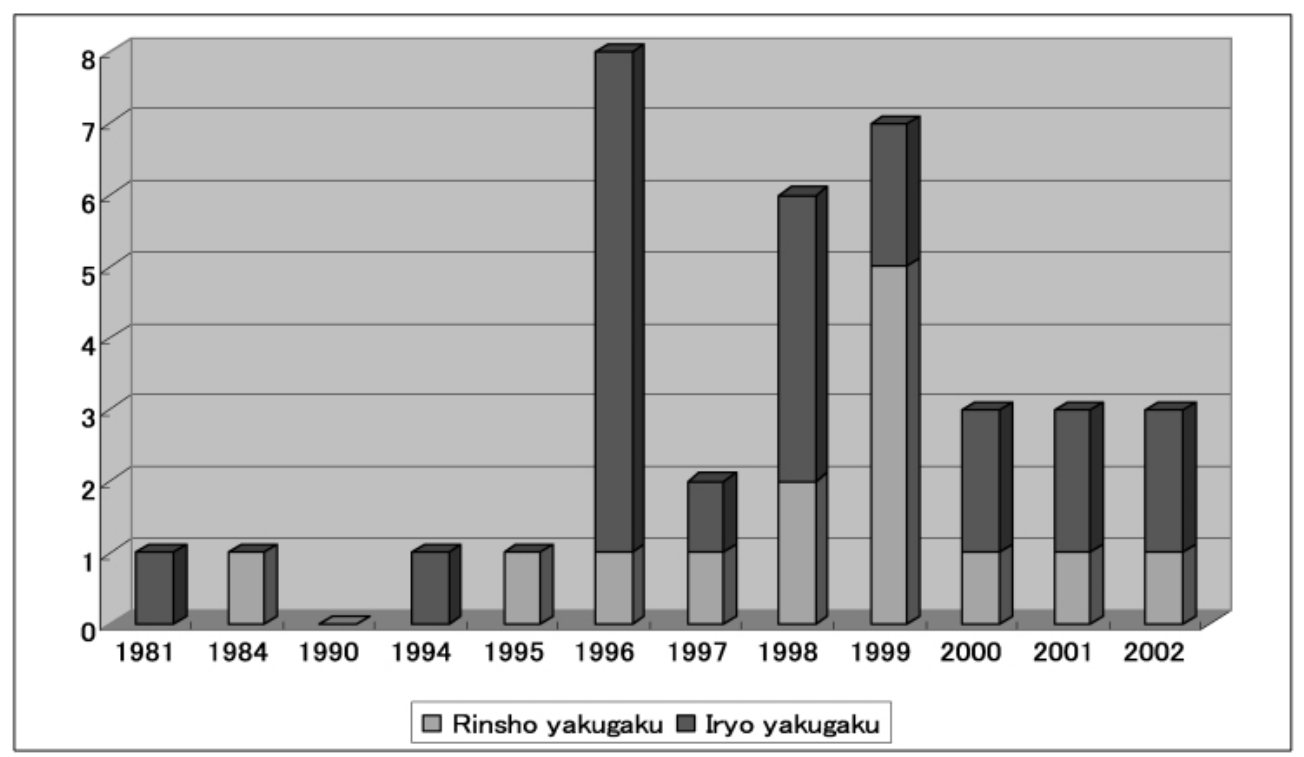

Fig. 5. The Year of Established a Course "Rinsho Yakugaku” or “Iryo Yakugaku” in Schools of Pharmacy

although a specific distinction between these two terms has been identified.

The Movement in the Use of the Terminology "Rinsho Yakugaku" and "Iryo Yakugaku' as Reflected in Practice Use of the terms "Rinsho yakugaku" and "Iryo yakugaku" at the Congress of the Pharmaceutical Society of Japan in 2002 was examined. The program titles for presentations were analyzed and classified.

For example:

- The presentation of [Establishment and evaluation for injectable drug dispensing system correspond to risk management] is "risk management"

- The presentation of [Function of glutamic acid transporter developing in cerebellum] is "biochemistry",

- The presentation of [Patient's Complaint for symptom and Presumption of drug adverse effect with using evaluation of patient's background, 11 . Renal failure] is "Drug adverse effect"

These classified titles of presentations were allocated to six groups; "Rinsho yakugaku”, "Iryo yakugaku", "Shakai yakugaku (Social pharmacy)", "Yakuzaigaku (Pharmaceutics)", "Kiso yakukaga- 
Table 4. Categorized the Subjects in 122nd Congress of the Pharmaceutical Society of Japan

\begin{tabular}{|c|c|}
\hline Category & Categorized items of the subject \\
\hline Rinsho yakugaku & $\begin{array}{l}\text { Monitoring } \cdot \text { Appropriate use of drug } \cdot \text { Drug adverse effect } \cdot \text { Drug interaction } \cdot \text { Pharmacotherapy (resistant to an- } \\
\text { tibiotic etc) } \cdot \text { Pathophysiology } \cdot \text { Cases } \cdot \text { Clinical research } \cdot \text { Clinical protocol }\end{array}$ \\
\hline Iryo yakugaku & $\begin{array}{l}\text { Risk management } \cdot \text { DI } \cdot \text { Patient information and others } \cdot \text { Clinical pass } \cdot \text { Pharmacoeconomics } \cdot \text { Communication } \cdot \\
\text { Pre-avoid } \cdot \text { Drug evaluation and Clinical evaluation etc } \cdot \text { Drug efficacy }\end{array}$ \\
\hline $\begin{array}{l}\text { Shakai yakugaku } \\
\text { (Sociel Pharmacy) }\end{array}$ & $\begin{array}{l}\text { Systems } \cdot \text { Database } \cdot \text { Environment and Infection } \cdot \text { Post Marketing Survey } \cdot \text { Cooperation with other health care } \\
\text { worker } \cdot \text { Health care for elderly people } \cdot \text { Patient or other health care worker education } \cdot \text { Nutrition }\end{array}$ \\
\hline $\begin{array}{l}\text { Yakuzaigaku } \\
\text { (Pharmaceutics) }\end{array}$ & $\begin{array}{l}\text { Pharmacy practice } \cdot \text { Pharmacy administration } \cdot \text { Dispensing (manual making etc) } \cdot \text { Drug preparation and com- } \\
\text { pounding alteration } \cdot \text { Pharmaceutical Preparation and Pharmaceutics } \cdot \text { Medical equipment }\end{array}$ \\
\hline $\begin{array}{l}\text { Kiso-yakukagaku } \\
\text { (Basic pharmace- } \\
\text { utical science) }\end{array}$ & $\begin{array}{l}\text { Biochemistry and Pharmacology (enzyme } \cdot \text { transporter } \cdot \text { angiogenesis etc }) \cdot \text { Pharmacokinetics } \cdot(\text { Phar- } \\
\text { macodynamics }) \cdot \text { Drug metabolism } \cdot \text { Genetics }\end{array}$ \\
\hline Others & Herbal medicine $\cdot$ Education etc \\
\hline
\end{tabular}

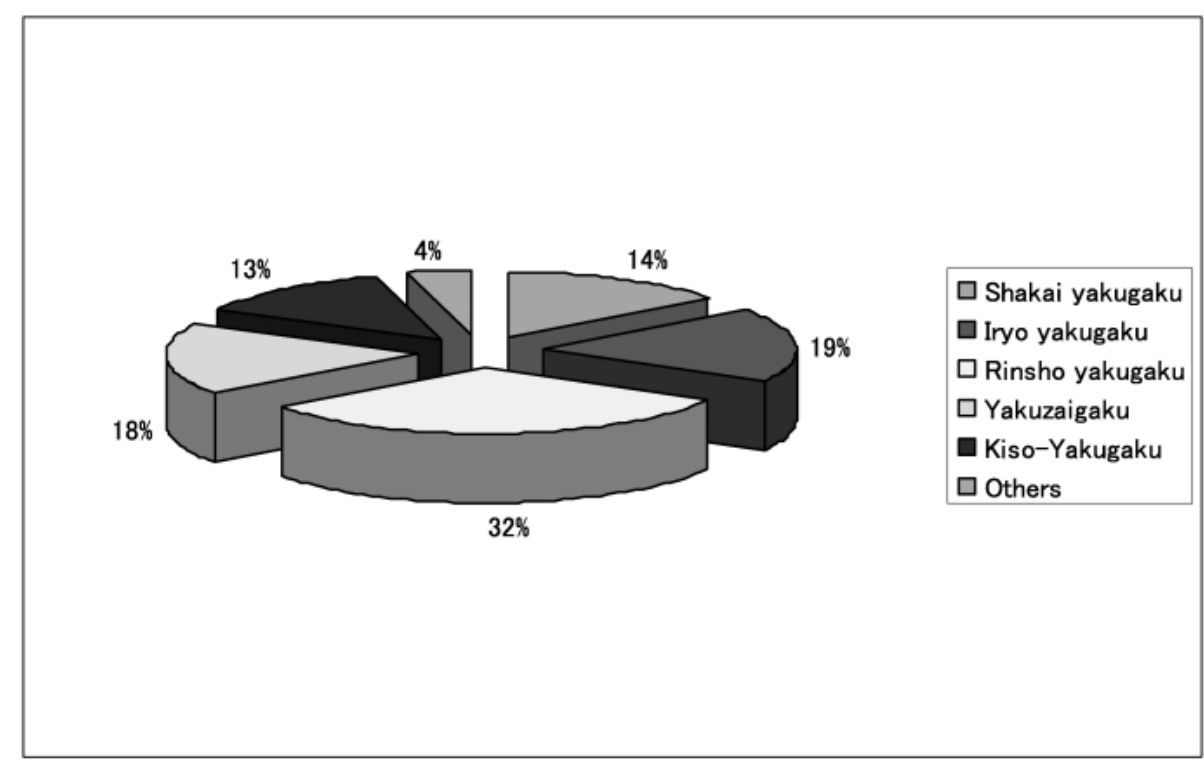

(Total number of subjects : 368 )

Fig. 6. Categorized the Subjects in the 122nd Congress of the Pharmaceutical Society of Japan Shakai yakugaku=Social Pharmacy, Yakuzaigaku=Pharmaceutics, Kiso-yakugaku=Basic Pharmaceutical Science.

$\mathrm{ku}$ (Basic pharmaceutical science)", and "Others", (Table 4). And as can be seen in Fig. 6, "Rinsho yakugaku" was $32 \%$, "Iryo yakaugaku" was $19 \%$, "Shakai yakugaku (Social pharmacy)" was 14\%, "Yakuzaigaku (Pharmaceutics)", was 18\%, "Kiso yakukagaku (Basic pharmaceutical science)" was 13 $\%$ and "Others" was $4 \%$. That is to say, category "Rinsho yakugaku" was most often found of the six categories. However, this field, as defined by the Pharmaceutical Society of Japan, was categorized as a field of "Iryo yakugkau", in addition, even though there were many "Rinsho yakugaku" items in this Iryo yakugaku field, there was no field called "Rinsho yakugaku" in the Pharmaceutical Society of Japan. It is inferred that, in the Pharmaceutical Society of Japan, "Iryo yakugaku" includes "Rinsho yakuga$\mathrm{ku}$ " and has more comprehensive meaning on the grounds that the "Iryo yakugaku" field covered many presentation titles included in "Rinsho yakuga$\mathrm{ku}$ '.

Also, the workplace to which each presenter belonged was examined in order to know the extent of recognition for "Rinsho yakugaku" and "Iryo yakugaku". And as can be seen Fig. 7, presenters from universities were $14 \%$, university hospitals were $28 \%$, other setting hospitals were $17 \%$, enterprises 


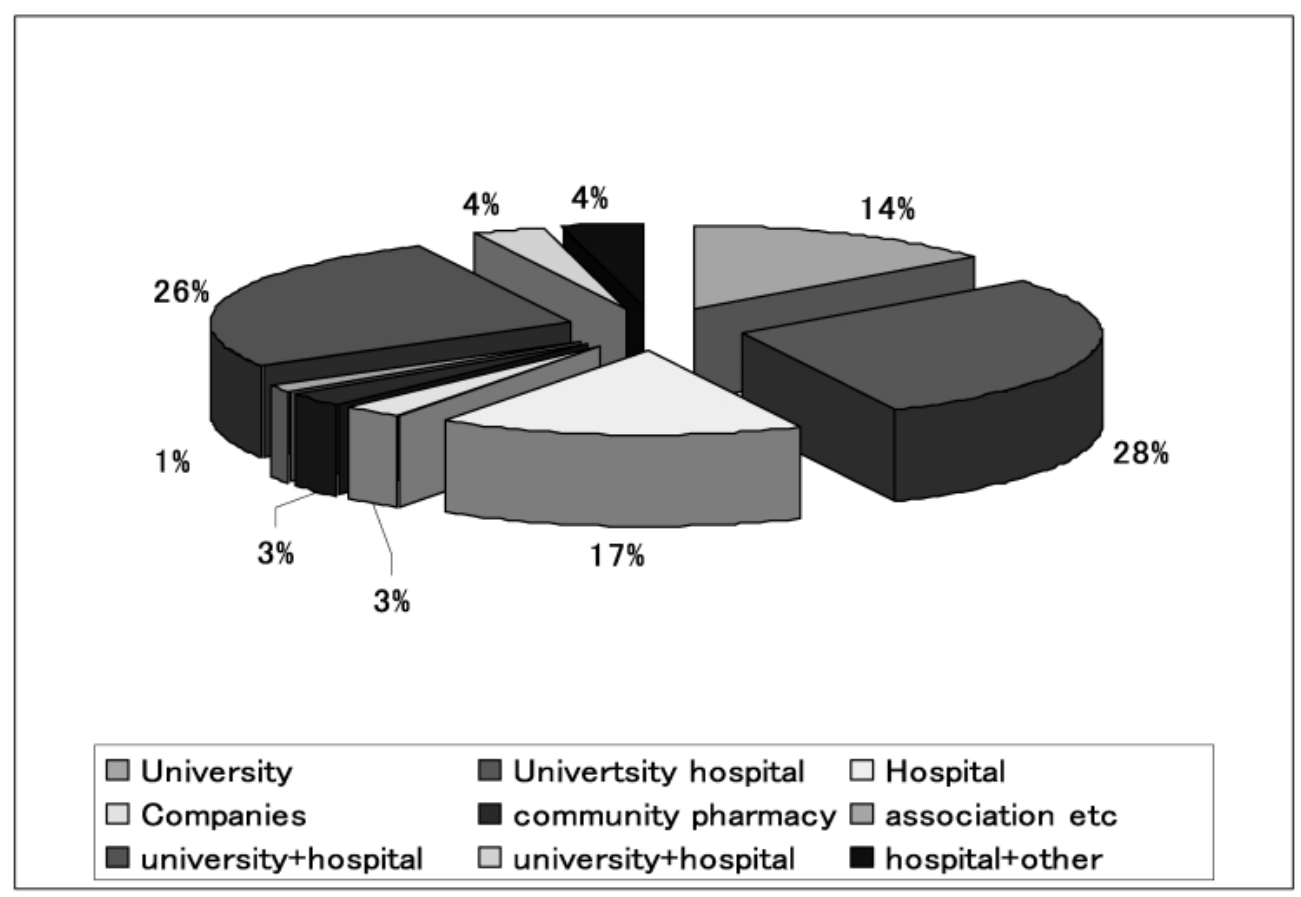

(Total number of subjects : 368 )

Fig. 7. Presenters' Workplaces in the 122nd Congress of the Pharmaceutical Society of Japan

(pharmaceutical company) were $3 \%$, community pharmacies were $3 \%$, pharmaceutical associations or pharmaceutical societies were $1 \%$. Also for collaborative research, presenters from university and hospital were $26 \%$, university and other was $4 \%$, hospital and other was $4 \%$. Therefore, the total number of presentations from hospital presenters was 71 $\%$, that is, the majority of the presentations were from hospitals in this field of "Iryo yakugaku". Also it is inferred that many presenters used the term "Rinsho yakugaku" in this field on the grounds that most of these presentations contained materials related to patient care areas.

As a result, it was verified that, in the presentations at the Congress of Pharmaceutical Society of Japan, "Iryo yakugkau" has wide (comprehensive) scope including basic pharmaceutical science in the university, hospital practice relevant to "Rinsho yakugaku", drug therapy and pharmacy practice in community pharmacy, etc.

\section{CONCLUSION}

In recent years, the situation for pharmacists has rapidly changed. Pharmacists have tried to change their role beyond simply dispensing, that is, hospital pharmacists have shifted their role to patient care and community pharmacists have begun to provide pharmaceutical care services to people. In order that pharmacists perform these services, it is necessary to develop pharmacy education programs related to these roles. Here, for the first step, the terms related to these pharmacists' roles were examined with the purpose of a structured understanding these terms. The terms "Rinsho yakugaku”, "Iryo yakugaku”, “clinical pharmacy" and "pharmaceutical care" were examined by their use in the literature. Frequency in the use of these terms was found in almost the same level, and it was confirmed that these words had overlap in the same literature. In consequence, a clear difference was not found among these terms, and it was verified that these terms have been used imprecisely. In historical change, the term of "Iryo yakugaku" existed before appearance of the term of "Rinsho yakugaku". Added to this, it is confirmed that the term "Rinsho yakugaku" began to use at almost the same time when the concept of "clinical pharmacy" was introduced, thus, it is inferred that "Rinsho yakugaku" seemed a translation word for "clinical pharmacy". Recently the term of "Iryo yakugaku" has been used more than "Rinsho yakugaku". The result from the use of these terms and the implementing of "Rinsho yakugaku" or "Iryo yakugaku" courses in the 
schools of pharmacy were analyzed. These courses had been rapidly established in the 1990's concurrent to the result of chronological occurrence in the use of these terms. Furthermore, the courses designated "Iryo yakugaku" has now been established more substantially than courses described as "Rinsho yakugaku". In other words, the reverse phenomenon has occurred. However, the reason for the choice in describing these courses, and difference in meaning for these terms are still unclear. At the Congress of the Pharmaceutical Society of Japan, for instance, the term of "Rinsho yakugaku" was not used. Although the section on Iryo yakugaku was instituted and many subjects of pharmacists' services in patient care areas of the hospital and basic pharmaceutical sciences were presented, the difference of theses terms were not clarified. However, it appears that term of "Iryo yakugaku" is used by the Pharmaceutical Society of Japan as having a comprehensive scope including "Rinsho yakugaku" based on the presentations at $\begin{aligned} \text { Iryo yakugaku } \fallingdotseq & \text { Pharmaceutical Services } \\ & \text { (All services that pharmacists are able to provide, not only those that } \\ & \text { involve prescribed medication. This would include nonprescription } \\ & \text { medication, herbal medication, bandages, health equipment, nutritional } \\ \text { products, maintaining medication records, ensuring that legal } & \text { requirements are followed and that legal records are maintained, clinics } \\ & \text { for disease detection or monitoring, diagnostic equipment and supplies) }\end{aligned}$

- Patient Focussed Care

-- Pharmaceutical Care $\fallingdotseq$ Chiryo yakugaku (Care yakugaku)

- To promote health and prevent disease

To solve drug related problem so that patient is provided optimal health-related quality of life

-. Rinsho yakugaku $\fallingdotseq$ clinical pharmacy

(Patient-oriented drug therapy in hospital patient care areas)

- To be directly involved in patients' pharmacotherapy

- To participate in health system activities as a health professional

- To provide information to other health care workers and patients

- The above activities are in addition to providing prescription drugs, food, OTC, supplements, complementary therapy (ex. Herbal medicine)

- Dispensing medication,

- dispensing of prescriptions, selling of nonprescription drugs and herbals etc

- Involvement in traditional health practices and complementary practice such as Kampo (Japanese herbal medicine), acupuncture, aromatherapy, etc. that prevent a disease or maintain health,

- Management of human resources, financial and operational activities

- Services for Groups of Patients or the Public

- Health screening (screening for diabetes etc)

- Cooperative health care with other health care workers

- Health economics (Pharmacoeconomics)

- Clinical research in pharmacy practice

- Establishing clinical guidelines for monitoring patients in chronic disease programs (elderly, disease states)

- Post Marketing Surveillance

- Activities to improve health care (health promotion activities)

Fig. 8. The Scope and Content of Pharmacists' Activities 
the conference.

The meaning of these terms and the scope of pharmacists' roles related to these terms was reviewed and it was found that "Rinsho yakugaku" is the most appropriate translation for "clinical pharmacy". However, it was not found that there is an appropriate translation for "pharmaceutical care" and an appropriate English word for "Iryo yakugaku". Therefore, we proposed that translation for "pharmaceutical care" is "Chiryo yakugaku" and English for "Iryo yakugaku" is "pharmaceutical service". The scope of pharmacists' services related to those terms is presented in Fig. 8. It is proposed that "Iryo yakugaku (pharmaceutical service)" includes both "Rinsho yakugaku (clinical pharmacy)" and "Chiryo yakugaku (pharmaceutical care)".

In order to demonstrate the social requirement for pharmacists, it is necessary to review descriptions of pharmacy services and initiatives as well as pharmacy education programs and to compare them with the roles that have been accepted internationally and then to develop new pharmacy education programs in Japan in this context.

\section{ACKNOWLEDGMENTS}

We would heartfully like to thank Professor Takehiko Yajima (Dean of the School of Pharmaceutical Sciences, Toho University) for his helpful discussions and supports. We also thank Professor Ichiro Kudo (the School of Pharmacy Pharmaceutical Sciences, Showa University) for his suggestions.

\section{REFERENCES}

1) Information of Nitiyaku No. 101, Journal of the Japan Pharmaceutical Association, 53, 181 -183 (2001).

2) Sawada Y., Yakkyoku, 52, 33-46 (2001).

3) Sawada Y., Gekkan Yakuji, 43, 891-905 (2001).

4) Kouhara T., The Journal of the Toyaku, 24 (9) , 53-55 (2002).

5) Ichikawa A., Pharmaceutical Society of Japan, "Model Core Curriculums for Pharmacy Education", Pharmacia, 38, 608-609
(2002) .

6) Tomita M., Private Pharmaceutical College Association, "Model Core Curriculums for changes in Pharmacy Education", Journal of the Japan Pharmaceutical Association, 54, 149 -154 (2002).

7) Information of Nitiyaku No. 114, Journal of the Japan Pharmaceutical Association, 54, 5-8 (2002).

8) Ninomiya T., Aizawa Y., Kawasaki K., Saito T., Sezaki H., Hayashida A., Takagi K., Pharmacia, 13, 37-43 (1977).

9) Takagi K., Watanuki Y., Turufuji S., Pharmacia, 13, 294-295 (1977).

10) Ebihara A., Hayashida A., Kasuya Y., Horioka M., Ninomiya T., Tatsuno T., Kubo S., Pharmacia, 13, 909-915 (1977).

11) Research Group on Improvement of Pharmaceutical Education, "The View of Pharmaceutical Education Model Curriculum Development-Baseline for Pharmaceutical Education and Pharmacy Education," Pharmacia, 31, 1220-1230 (1995).

12) Kayser S. R., Gekkan Yakuji, 38, 155-160 (1996).

13) FIP Statement of Pharmaceutical Care, Journal of the Japan Pharmaceutical Association, 50, 159-161 (1998).

14) Role of Pharmacist in Health Care SystemReport of 3rd WHO Meeting, Journal of the Japan Pharmaceutical Association, 50, 113117 (1998).

15) Tanaka Y., Pharmacia, 35, 1243-1245 (1999).

16) Yamamoto N., Pharmacia, 37, 1027-1030 (2001).

17) Hayase Y., "Problem of the Separation of Prescription and Dispensing," Yakugaku Zasshi, 123, 121-132 (2003).

18) Hayashi S., "The Expected Role of Community Pharmacist in Society," Yakugaku Zasshi, 123, 163-171 (2003).

19) Tanaka Y., "Pharmaceutical Care"-Kyoiku to Jissen ni mukete no Katudo-, Pharmacia, 35, 1243-1245 (1999). 